\title{
Compaction of a Rock Fracture Moderated by Competing Roles of Stress Corrosion and Pressure Solution
}

\author{
Hideaki Yasuhara, ${ }^{1}$ and Derek Elsworth ${ }^{2}$
}

\begin{abstract}
Unusually rapid closure of stressed fractures, observed in the initial stages of loading and at low temperatures, is examined using models for subcritical crack growth and pressure solution. The model for stress corrosion examines tensile stress concentrations induced at the Hertzian contact of propping fracture asperities, and mediates fracture growth according to a kinetic rate law. Conversely, pressure solution is described by the rate-limiting process of dissolution, resulting from the elevated stresses realized at the propping asperity contact. Both models are capable of following the observed compaction of fractures in novaculite. However, closure rates predicted for stress corrosion cracking are orders of magnitudes faster than those predicted for pressure dissolution. For consistent kinetic parameters, predictions from stress corrosion better replicate experimental observations, especially in the short-term and at low temperature when mechanical effects are anticipated to dominate. Rates and magnitudes of both stress corrosion and pressure solution are dependent on stresses exerted over propping asperities. Rates of closure due to stress corrosion cracking are shown to be always higher than for pressure solution, except where stress corrosion ceases as contact areas grow, and local stresses drop below an activation threshold. A simple rate law is apparent for the progress of fracture closure, defined in terms of a constant and an exponent applied to the test duration. For current experimental observations, this rate law is shown to replicate early progress data, and shows promise to define the evolution of transport properties of fractures over extended durations.
\end{abstract}

Key words: Stress corrosion, pressure solution, fracture compaction, geochemistry.

\section{Introduction}

An understanding of the flow and transport characteristics of fractured rocks is of significant importance to the effective recovery of energy resources from the subsurface, and for the safe and long-term isolation of energy-related by-products (e.g., high level radioactive wastes and $\mathrm{CO}_{2}$ ). Fluid flow within low-permeability rock masses is often dominated by transport in through-cutting fractures. Changes in the ambient stress and temperature conditions may affect the transport characteristics of these conduits through combined mechanical and chemical effects. Enhancement may result from mechanical

${ }^{1}$ Department of Civil and Environmental Engineering, Ehime University, Matsuyama 790-8577, Japan. E-mail: hide@dpc.ehime-u.ac.jp

2 Department of Energy and Geo-Environmental Engineering, Pennsylvania State University, University Park, PA 16802, USA. 
dilation as an adjunct to shear deformation with overprinted effects of chemical dissolution within the fracture void. Whereas degradation may result from reversible elastic compaction or irreversible inelastic crushing (i.e., mechanical failure) of the propping asperities, dissolution at contacting asperities, and clogging of the fracture void by mineral precipitation. Mechanical effects occur near-simultaneously with deformation, but chemical effects may progress on an extended timescale — rate-limited either by kinetics or transport. Understanding these combined effects, and their spatial and temporal controls, is of significant importance in understanding the evolution of permeability in fractures over both the short- and the long-term.

Specifically, mechanically- and chemically-mediated processes of stress corrosion and pressure solution may result in the degradation of fracture permeability through compaction driven by fracturing (or crushing) of the propping asperities and by dissolution at contacting asperities, respectively. These mechanisms will be distinct, but the resulting responses may be similar, or indeed indistinguishable.

When local tensile stresses result from the compressive loading of contacting asperities, "sub-critical" or "quasi-static" cracking may result (e.g., LAWN and WILSHAw, 1975; AtKinson, 1984; Scholz, 1990), leading to a time-dependent or progressive failure. Specifically, subcritical crack growth in the presence of water is believed to be facilitated by chemical reaction - and the resulting process termed stress corrosion (ATKINSON, 1979). Under hydrothermal conditions where fluid-rock reaction is enhanced, this process has been rigorously investigated to both understand and ultimately predict the development of fracturing of the rock matrix (e.g., Atkinson and Meredith, 1981; Dove, 1995; Feng et al., 2001; NARA and KANEKo, 2005), and is also applied to describe the compaction behavior in granular aggregates (SHUTJENs, 1991; CHESTER et al., 2004; KARNer et al., 2003). Notably, CHESTER et al. (2004) conclude that under low effective pressures the subcritical-cracking-induced creep may be a dominant mechanism for granular compactions at $150^{\circ} \mathrm{C}$ or less. This study examines for the first time the role of sub-critical crack growth to the evolution of compaction and permeability in rock fractures.

Pressure solution incorporates three serial processes; mineral dissolution at stressed contacts, diffusive transport of this material along the intervening thin film of water, and ultimate deposition of the mineral matter at the pore wall. This typically results in the loss of porosity, and a reduction in permeability. This process is implicated as the principal mechanism of diagenetic compaction and deformation in sedimentary rocks, which has been studied in detail (e.g., Weyl, 1959; Robin, 1978; Rutter, 1976; Raj, 1982; Dewers and HAJASH, 1995). Many phenomenological and theoretical models also have been developed to describe the progress of this mechanically- and chemically-dependent behavior in both aggregates (LEHNER, 1995; LEMÉE and GUÉGUEN, 1996; RENARD et al., 1997; Revil, 1999), and in rock fractures (YASUHARA et al., 2004).

In this study, two conceptual models accommodating either stress corrosion or pressure solution, are presented to examine the evolution of fracture aperture within a sample of novaculite containing a natural fracture. The observed enigmatic response 
comprises an initial rapid reduction in aperture, followed by a logarithmic deceleration in closure (PolaK et al., 2003; YasuHara et al., 2006a). To describe this response we first present models which separately account for stress corrosion and pressure solution, and then apply these to represent and explain experimental observations. Finally, the effects of these individual mechanisms on rates of fracture closure are examined in detail, to define the pressure and temperature dependency of the response.

\section{Mechanisms of Fracture Compaction}

Two viable mechanisms capable of contributing to the compaction of fractures are examined: subcritical crack growth via stress corrosion, and pressure solution. Methods to follow the evolution of these processes are developed and subsequently applied to the specific geometry of a rough contacting fracture, enabling the evolution of fracture aperture to be followed in time.

\subsection{Stress-corrosion-mediated Compaction}

Stress corrosion is one of the dominant mechanisms contributing to subcritical crack growth in brittle materials subject to extensional stresses. Typically, the relation between the crack growth velocity and the stress intensity factor, which is a measure to accurately predict the stress state near the tip of a crack and clearly defined in the following, is categorized into three regions as shown in Figure 1 (Atkinson, 1984; Freiman, 1984; DunNING et al., 1993). In regions 1 and 2 the kinetics of chemical reactions at the crack tip controls crack growth, and the crack velocity increases as activity of the stress corrosion agent is raised. In contrast, region 3 represents the transition from stress-corrosionmediated cracking to mechanical rupture for species bonds likely insensitive to the chemical environment (Evans, 1972; Freiman, 1984). In regions 2 and 3 crack growth (or fracturing) may be rapid (occasionally, $>10^{-1} \mathrm{~m} \mathrm{~s}^{-1}$ (ANDERSON and GREw, 1977; SEGALL, 1984), and these conditions are not considered here.

In region 1, a number of equations with respect to the crack velocity (or fracturing rate), $v$, have been proposed for mode I (i.e., a tensile-opening mode), generically given as,

$$
v=A \exp \left(\frac{-\Delta H}{R T}\right) f\left(K_{I}\right),
$$

where $A$ is the experimentally-determined pre-exponential factor, $\Delta H$ is the activation enthalpy. $f\left(K_{\mathrm{I}}\right)$ is a well-dined function of $K_{\mathrm{I}}$, the stress intensity factor for mode I, and may be expressed as power (e.g., CHARLES, 1958) or exponential (e.g., WiEDERHORN and Bolz, 1970; Freiman, 1984; Dove, 1995) functions. The latter exponential forms are derived by accounting for the dissolution kinetics at a crack tip. Specifically, Dove (1994) has rigorously investigated the dissolution kinetics of quartz under the wide range of temperature $\left(25\right.$ to $300^{\circ} \mathrm{C}$ ) and $\mathrm{pH}$ (2 to 12$)$ conditions, and defined the crack velocity by 


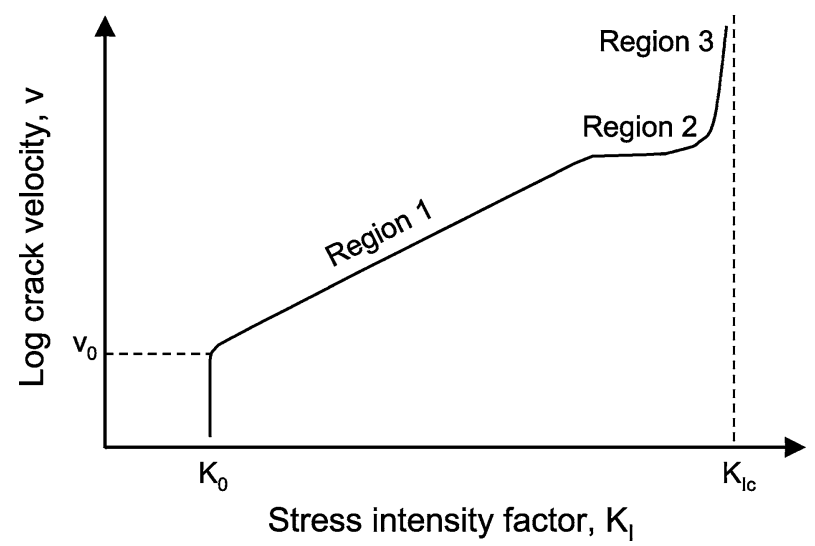

Figure 1

Schematic of the relation between crack growth velocity and stress intensity factor with various active regions (after AtKinson, (1984)

assuming that the chemical dissolution at a crack tip directly controls the subcritical cracking kinetics, given as (Dove, 1995),

$$
\begin{aligned}
v_{S i-O}= & A_{H 2 O} \exp \left(\frac{-\Delta H_{H 2 O}}{R T}\right) \exp \left(b_{H 2 O}^{*} K_{I}\right)\left(\theta_{S i-O}^{H 2 O}\right) \\
& +A_{O H^{-}} \exp \left(\frac{-\Delta H_{O H^{-}}}{R T}\right) \exp \left(b_{O H^{-}}^{*} K_{I}\right)\left(\theta_{S i-O}^{O H^{-}}\right),
\end{aligned}
$$

where $A_{i}$ is the experimentally-determined pre-exponential factor, $\Delta H_{i}$ is the activation enthalpy, $R$ is the gas constant, $T$ is the temperature, $b_{i}^{*}$ is the experimentally-determined constant derived from the geometry of crack tip, and $\theta_{\mathrm{Si}-\mathrm{O}}^{i}$, always satisfying $\theta_{\mathrm{Si}-\mathrm{O}}^{\mathrm{H}_{2} \mathrm{O}}+\theta_{\mathrm{Si}-\mathrm{O}}^{\mathrm{OH}^{-}}=1$, is the fraction of Si-O reacting with molecular water or hydroxyl ions, and is in detail identified at various $\mathrm{pH}$ conditions ranging from 2 to 12 (Dove, 1994). Note that at the low (i.e., $\theta_{\mathrm{Si}-\mathrm{O}}^{\mathrm{H}_{2} \mathrm{O}}=1, \theta_{\mathrm{Si}-\mathrm{O}}^{\mathrm{OH}^{-}}=0$ ) or high $\mathrm{pH}$ (i.e., $\theta_{\mathrm{Si}-\mathrm{O}}^{\mathrm{H}_{2} \mathrm{O}}=0, \theta_{\mathrm{Si}-\mathrm{O}}^{\mathrm{OH}^{-}}=1$ ) conditions, the dissolution kinetics of quartz is strongly controlled by increased susceptibility of Si-O bonds to reaction with molecular water or hydroxyl ions, respectively. Dove $(1994 ; 1995)$ has rigorously examined these crucial parameters presented in Eq. (2) and identified them for quartz - those used in the following analyses are systematically tabulated in Table 1. Correspondingly, the crack velocity in Eq. (2) is calculated as evaluating the stress intensity factor, $K_{\mathrm{I}}$.

The stress intensity factor is defined by AtKinson (1987) in terms of the stresses exerted close to the crack tip, given as,

$$
K_{\mathrm{I}}=\lim _{r \rightarrow 0}\left[\sigma_{y}(2 \pi r)^{1 / 2}\right],
$$

where $\sigma_{y}$ is the tensile stress applied at or close to the crack tip, and $r$, parallel to the crack growth direction, is the infinitesimal distance from the crack tip. Assuming that the 
Table 1

Definition of parameters and values used in the analysis

\begin{tabular}{|c|c|c|c|}
\hline Parameters & Definition & Values & Unit \\
\hline$A$ & constant in Eq. (10) & 5.0 & - \\
\hline$A_{\mathrm{H} 2 \mathrm{O}}^{\mathrm{a}}$ & pre-exponetial factor & $1.12 \times 10^{-4} T$ & $\mathrm{~m} \mathrm{~s}^{-1}$ \\
\hline$A_{\mathrm{OH}-}^{\mathrm{a}}$ & pre-exponetial factor & $2.51 \times 10^{3} T$ & $\mathrm{~m} \mathrm{~s}^{-1}$ \\
\hline$b$ & local aperture & & $\mathrm{m}$ \\
\hline$<b>$ & equivalent aperture & & $\mathrm{m}$ \\
\hline$b_{0}$ & reference-stress aperture & $\begin{array}{l}1.25 \times 10^{-5} \text { for NovaI } \\
1.85 \times 10^{-5} \text { for } \text { NovaII }^{\mathrm{c}}\end{array}$ & $\mathrm{m}$ \\
\hline$b_{r}$ & residual aperture & $2.50 \times 10^{-6}$ & $\mathrm{~m}$ \\
\hline$b_{\mathrm{H}_{2} \mathrm{O}}^{*}{ }^{a}$ & constant derived from geometry of crack tip for $\mathrm{H}_{2} \mathrm{O}$ & $2.69 \times 10^{-5}$ for quartz & $\mathrm{N}^{-1} \mathrm{~m}^{3 / 2}$ \\
\hline$b_{\mathrm{OH}-}^{*}{ }^{*}$ & constant derived from geometry of crack tip for $\mathrm{OH}^{-}$ & $1.78 \times 10^{-5}$ for quartz & $\mathrm{N}^{-1} \mathrm{~m}^{3 / 2}$ \\
\hline$c$ & one-half crack length & & $\mathrm{m}$ \\
\hline$d_{c}$ & diameter of the asperity contact & & $\mathrm{m}$ \\
\hline$E$ & Young's modulus & $7.00 \times 10^{10}$ & $\mathrm{~Pa}$ \\
\hline$E_{a}$ & activation energy & $7.00 \times 10^{4}$ for quartz & $\mathrm{J} \mathrm{mol}^{-1}$ \\
\hline$E_{m}$ & heat of fusion & $8.57 \times 10^{3}$ for quartz & $\mathrm{J} \mathrm{mol}^{-1}$ \\
\hline$\Delta H^{a}$ & activation enthalpy for $\mathrm{H}_{2} \mathrm{O}$ & $6.60 \times 10^{4}$ & $\mathrm{~J} \mathrm{~mol}^{-1}$ \\
\hline$\Delta H_{\mathrm{OH}-}^{\mathrm{H}_{2} \mathrm{O}}$ & activation enthalpy for $\mathrm{OH}^{-}$ & $8.27 \times 10^{4}$ & $\mathrm{~J} \mathrm{~mol}^{-1}$ \\
\hline$k_{+}$ & dissolution rate constant & & $\mathrm{mol} \mathrm{m}^{-2} \mathrm{~s}^{-1}$ \\
\hline$k_{+}^{0 \mathrm{~d}}$ & reference dissolution rate constant & 1.59 & $\mathrm{~mol} \mathrm{~m}^{-2} \mathrm{~s}^{-1}$ \\
\hline$K_{0}^{+}$ & stress corrosion limit & & $\mathrm{N} \mathrm{m}^{-3 / 2}$ \\
\hline$K_{\mathrm{I}}$ & stress intensity factor & & $\mathrm{N} \mathrm{m}^{-3 / 2}$ \\
\hline$M_{\text {diss }}$ & dissolved mass & & $\mathrm{kg}$ \\
\hline$r$ & infinitesimal distance from crack tip & $1.00($ to 5.00$) \times 10^{-6}$ & $\mathrm{~m}$ \\
\hline$R$ & gas constant & 8.31 & $\mathrm{~J} \mathrm{~mol}^{-1} \mathrm{~K}^{-1}$ \\
\hline $\bar{R}$ & nominal area of the fracture & & - \\
\hline$R_{c}$ & contact-area ratio & & - \\
\hline$v_{\mathrm{Si}-\mathrm{O}}$ & crack velocity for quartz & & $\mathrm{m} \mathrm{s}^{-1}$ \\
\hline$T$ & temperature & & $\mathrm{K}$ \\
\hline$T_{m}$ & temperature of fusion & 1883 for quartz & $\mathrm{K}$ \\
\hline$V_{m}$ & molar volume & $2.27 \times 10^{-5}$ for quartz & $\mathrm{m}^{3} \mathrm{~mol}^{-1}$ \\
\hline$\theta_{\mathrm{Si}-\mathrm{O}}^{\mathrm{H} 2 \mathrm{O}}$ & fraction of $\mathrm{Si}-\mathrm{O}$ reacting with $\mathrm{H}_{2} \mathrm{O}$ & 0.99921 at $\mathrm{pH}=7^{\mathrm{a}}$ & - \\
\hline$\theta_{\boldsymbol{S i}-\boldsymbol{O}}^{\boldsymbol{O H} \overline{\boldsymbol{O}} \boldsymbol{O}}$ & fraction of $\mathrm{Si}-\mathrm{O}$ reacting with $\mathrm{OH}^{-}$ & 0.00079 at $\mathrm{pH}=7^{\mathrm{a}}$ & - \\
\hline$v$ & Poisson's ratio & 0.20 & - \\
\hline$\rho_{g}$ & density & $2.65 \times 10^{3}$ for quartz & $\mathrm{kg} \mathrm{m}^{-3}$ \\
\hline $\bar{\sigma}$ & average normal stress exerted over nominal fracture area & $\begin{array}{l}2.73 \times 10^{6} \text { for NovaI }^{b} \\
1.38 \times 10^{6} \text { for NovaII }^{c}\end{array}$ & $\mathrm{~Pa}$ \\
\hline$\sigma_{a}$ & normal stress exerted over contact area & & $\mathrm{Pa}$ \\
\hline$\sigma_{t}$ & tensile stress exerted over contact area & & $\mathrm{Pa}$ \\
\hline$\sigma_{y}$ & stress close to crack tip, normal to crack & & $\mathrm{Pa}$ \\
\hline
\end{tabular}

a, b, c, and d: Values from Dove (1994 and 1995), PolaK et al. (2003), YASUHARA et al. (2006a), and Dove et al. (1990), respectively

asperity contacts, schematically shown in Figure 2, within a fracture are in Hertzian contacts, a circumferential crack at or outside the contact may be generated in brittle materials (e.g., LAwn, 1998) - this crack is induced by the tensile stresses that reach maximum values just at the edge of the contacts, which is defined as $\sigma_{t}$, given by (JOHNSON, 1985), 


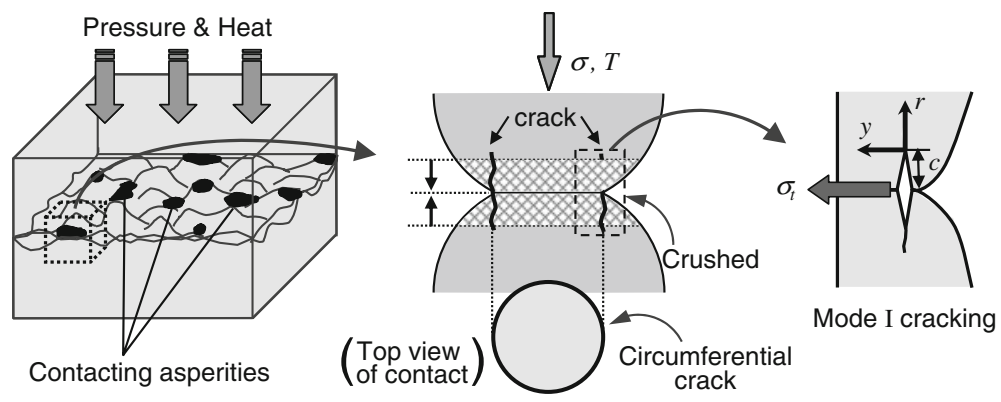

Figure 2

Schematic of fracture compaction induced by microcrack propagation. A rate of aperture reduction is assumed equivalent to a crack velocity. Microcracking, regarded as a Mode I opening, at the edge of the contact is promoted by stress corrosion at crack tips.

$$
\sigma_{t}=\frac{(1-2 v)}{2} \sigma_{a}
$$

where $v$ is the Poisson's ratio and $\sigma_{a}$ is the mean normal stress exerted over the contact area. The normal stress, $\sigma_{a}$, is simply defined to conform to the uniaxial condition, as (Hutchings, 1992),

$$
\sigma_{a}=\frac{\bar{R}}{R_{c}} \bar{\sigma}
$$

where $\bar{R}$ is the nominal area of the fracture, $R_{c}$ is the contact-area ratio, and $\bar{\sigma}$ is the average normal stress exerted over the nominal fracture area. The tensile stress at the edge of the contacts, $\sigma_{t}$, may be assumed equivalent to that exerted at or close to the crack tip, $\sigma_{y}$, when initial crack length at contacts and distance from the crack tip, $r$, are sufficiently small. Therefore, the stress intensity factor for mode I may be approximated by substituting $\sigma_{t}$ instead of $\sigma_{y}$ in Eq. (3), as,

$$
K_{I} \approx \sigma_{t}(2 \pi r)^{1 / 2}
$$

which is utilized in the analysis hereinafter.

When the crack velocity, $v_{\mathrm{Si}-\mathrm{O}}$, is assumed, as a first-order approximation, equivalent to that of the fracture closure (Figure 2), the evolution in aperture is defined as,

$$
\frac{d b}{d t}=-\left(1-R_{c}\right) \cdot v_{\mathrm{Si}-\mathrm{O}}
$$

This assumption may be justified in the specific case where the crack propagation simultaneously triggers cataclastic failure and deformation at the tips of the contacting asperities. Actually, such combined phenomena (i.e., the micro-cracking and cataclasis) are micrographically observed at grain contacts in brittle salt (dEN BROK et al., 1998). 


\subsection{Pressure-solution-mediated Compaction}

Pressure solution incorporates the serial processes of dissolution at contacting asperities, interfacial diffusion along the contact, and precipitation at the free face of the fracture void. The process is rate-limited by the slowest of the three processes, and this rate-limiting process will control the overall deformation (i.e., fracture closure). The dissolution is conveniently defined in terms of a dissolution mass flux, $d M_{\text {diss }} / d t$, the rate of addition of dissolved mass into solution at the interface, given as (YASUHARA et al., 2003),

$$
\frac{d M_{\mathrm{diss}}}{d t}=\frac{3 \pi V_{m}^{2}\left(\sigma_{a}-\sigma_{c}\right) k_{+} \rho_{g} d_{c}^{2}}{4 R T}
$$

where $V_{m}$ is molar volume of the solid, $\sigma_{c}$ is the critical stress that defines stress state where the compaction will effectively halt and reach equilibrium, $k_{+}$is the dissolution rate constant of the solid, $\rho_{g}$ is the density, $d_{c}$ is the diameter of the asperity contact. The dissolution rate constant, $k_{+}$, shows an Arrhenius-type dependence with temperature, given by,

$$
k_{+}=k_{+}^{0} \exp \left(-E_{a} / R T\right)
$$

where $k_{+}^{0}$ is the pre-exponential factor and $E_{a}$ is the activation energy. The critical stress, $\sigma_{c}$, is determined by considering the energy balance under applied stress and temperature conditions, given by (Revil, 1999, modified from STEPHENSON et al., 1992),

$$
\sigma_{c}=\frac{E_{m}\left(1-T / T_{m}\right)}{4 V_{m}}
$$

where $E_{m}$ and $T_{m}$ are the heat and temperature of fusion, respectively.

In a system far-from-equilibrium, and with dissolution prescribed as the process with the primary control on deformation (neither diffusion or precipitation contribute to strain), Eq. (8) may be rearranged in terms of the rate of aperture closure, $d b / d t$, as,

$$
\frac{d b}{d t}=-\frac{d M_{\mathrm{diss}}}{d t} \cdot \frac{1}{\rho_{g}} \cdot \frac{1-R_{c}}{(\pi / 4) d_{c}^{2}}=-\frac{3 V_{m}^{2} k_{+}^{0}\left(1-R_{c}\right)\left(\sigma_{a}-\sigma_{c}\right)}{R T} \exp \left(-\frac{E_{a}}{R T}\right) .
$$

This enables the rate of aperture reduction, mediated by pressure solution, to be straightforwardly evaluated.

\section{Comparison with Experimental Measurements}

These two conceptual models, for subcritical crack growth effects, and for pressure solution, are applied to examine the time-dependent evolution in fracture aperture obtained from the two companion experiments in stressed natural fractures of novaculite (hereinafter, referenced as Nova I (Polak et al., 2003) and Nova II 
(YASUhARA et al., 2006a), see Figure 3). In both cases the flow-through experiments are conducted on a natural fracture of Arkansas novaculite (LeE et al., 1991), at constant effective stresses of $2.73 \mathrm{MPa}$ for Nova I and $1.38 \mathrm{MPa}$ for Nova II and at elevated temperatures in the range $20-150{ }^{\circ} \mathrm{C}$. Distilled water is used as permeant and the system is chemically simple, conforming to the reaction $\mathrm{SiO}_{2}+2 \mathrm{H}_{2} \mathrm{O} \leftrightarrow \mathrm{Si}(\mathrm{OH})_{4}$. Evolution of fracture aperture and $\mathrm{Si}$ concentration has been measured throughout the experiments for 900 and $3150 \mathrm{hrs}$ in Nova I and Nova II, respectively, although Si concentrations
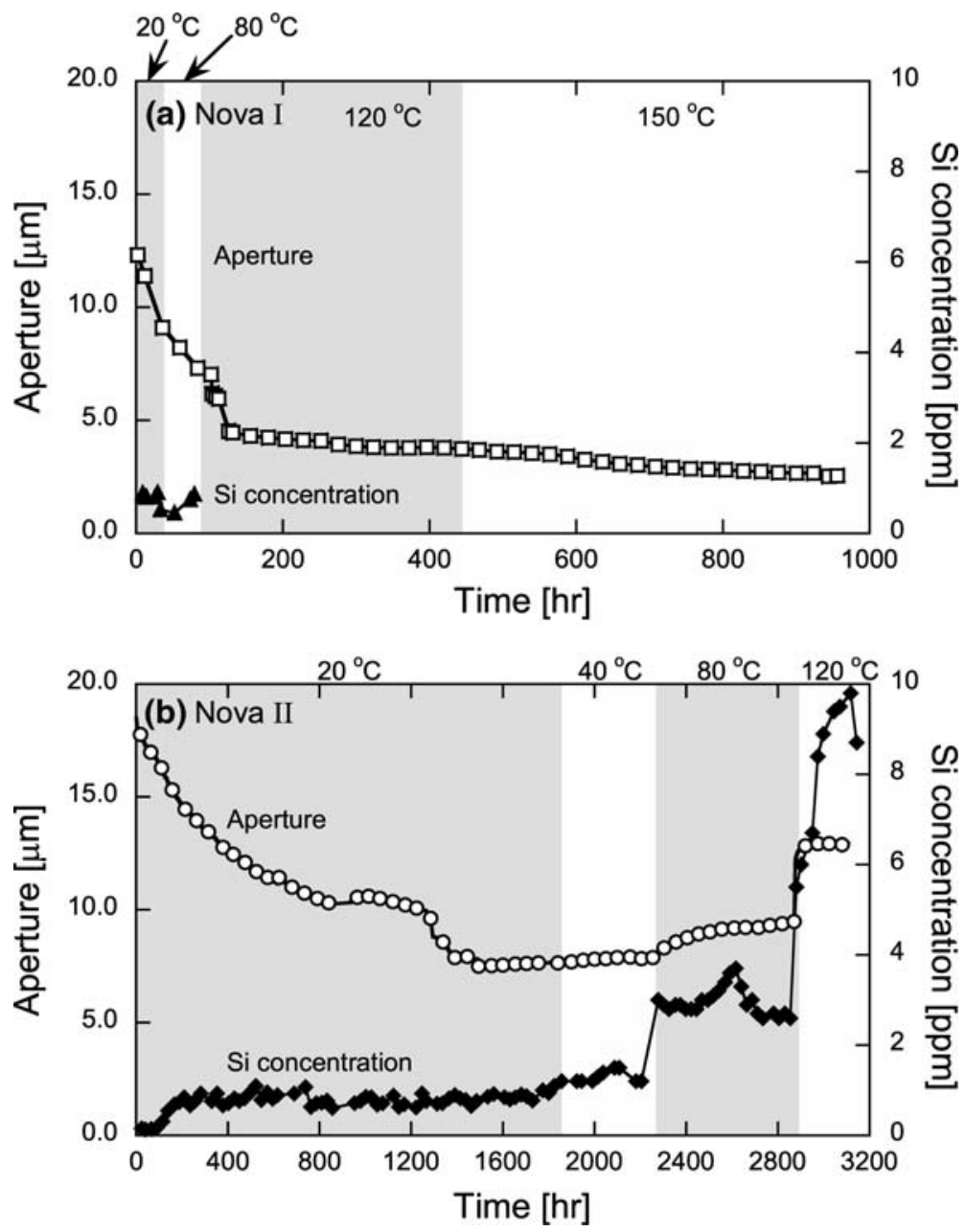

Figure 3

Evolution in fracture apertures and Si concentrations observed; (a) Nova I (after PoLAK et al., 2003) and (b) Nova II (after YASUHARA et al., 2006a). In both cases abrupt and significant reduction in fracture apertures are observed at the initiation of the experiment. In Nova II, Si concentrations observed increase with an increase in temperature due to temperature-enhanced solubility. 
are evaluated only for the first $100 \mathrm{hrs}$ in Nova I. The measured mineral effluents show a monotonic increase with an increase of temperatures prescribed in Nova II as shown in Figure 3. In both experiments (Nova I and II) an abrupt decrease in fracture aperture (inferred from the measured permeability) is observed in the early experimental periods, and at the lowest of the ambient temperatures. The Si concentrations measured in Nova I and II are significant $\left(\sim 1 \mathrm{ppm}\right.$ at $\left.20^{\circ} \mathrm{C}\right)$ and the conceptual analyses conclude, although the microstructures are not observed in pre- and post-experiments, that those dissolved minerals are derived largely from contacting asperities and less from free surfaces in fracture voids (PolaK et al., 2003; YASUHARA et al., 2006a). At $20^{\circ} \mathrm{C}$ and under low effective stress conditions, pressure solution for quartz may exert a diminishingly small influence on the compaction behavior or be inactive as experimentally observed using quartz aggregates (e.g., EliAs and HAJASH, 1992). This suggests that the abrupt aperture reductions measured in both experiments are attributed to mechanisms other than pressure solution. Actually, a conceptual model accounting for pressure solution alone (YASUHARA et al., 2004; 2006b) is incapable of replicating such a rapid reduction of permeability, although the subsequent evolution of aperture at elevated temperature is well-represented by the progress of pressure solution, motivating the quantification of an initiating mechanism (i.e., stress corrosion) that may describe the anomalous behavior.

In both models the stresses exerted over the contacting asperities are primary parameters controlling the overall rates of compaction (see Eqs. (2) and (11)). As compaction proceeds, the geometry of the fracture surfaces is irreversibly altered, likely resulting in an increase in the contact area and a subsequent decrease in stresses acting on the contacting asperities. However, the models defined are incapable of following such irreversibility (i.e., temporal change in contact area and exerted stresses). Accommodating this issue requires that the representative relation between the fracture aperture and contact area be defined, a priori. The relation may be defined in terms of residual aperture, $b_{r}$, and reference-stress aperture, $b_{0}$, as (YASUHARA et al., 2004) (Figure 4),

$$
\langle b\rangle=b_{r}+\left(b_{0}-b_{r}\right) \exp \left(-\left(R_{c}-R_{c 0}\right) a\right),
$$

where $\langle b\rangle$ is a mean aperture, $R_{c}$ and $R_{c 0}$ denote the contact-area ratio and the relative ratio at the reference stress, respectively, and $a$ is a constant. The relative ratio, $R_{c 0}$, may be evaluated by assuming that the Hertzian contacts are formed at contacting asperities, which would be a reasonable approximation at a very early time in the compaction process, given by,

$$
R_{c 0}=\left(\frac{3 \sigma_{\mathrm{eff}} \pi\left(1-v^{2}\right)}{4 E}\right)^{2 / 3}
$$

where $E$ represents Young's modulus.

The change in fracture aperture, $\langle b\rangle$, driven by stress corrosion (Eq. (7)) or pressure solution (Eq. (11)) may be simply evaluated from, 


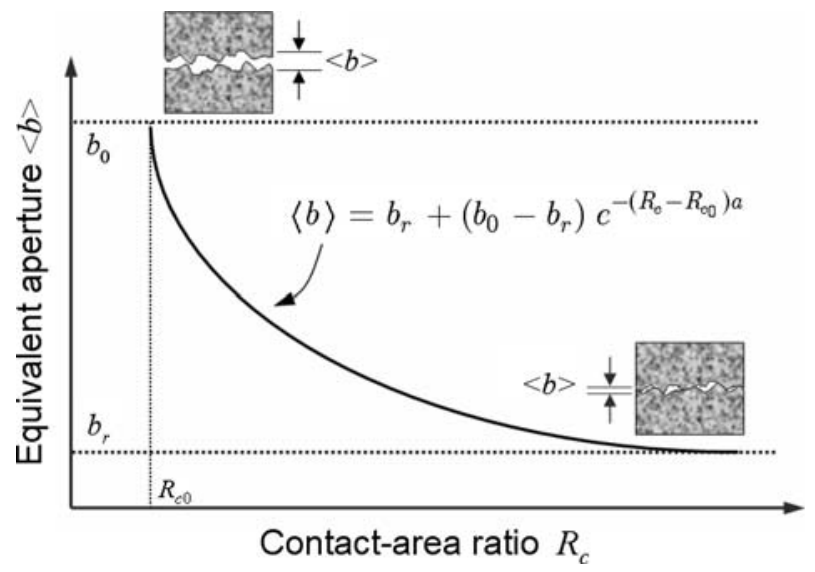

Figure 4

Relation between equivalent aperture and contact-area ratio. The relation corresponds to Eq. (9).

$$
\langle b\rangle_{t+\Delta t}=\langle b\rangle_{t}+\frac{d b}{d t} \Delta t
$$

Then, a new contact-area ratio and corresponding mean stress exerted over the contacting asperity is identified (see Eqs. (4), (5), and (12)). Repeating this calculation enables the irreversible, nonlinear evolution in fracture aperture moderated by stress corrosion or pressure solution to be followed consistently with time.

For early periods of the 950- (Nova I) and 3200-hr tests (Nova II), comparisons of the rates of fracture closure mediated by either stress corrosion or pressure solution, together with experimental measurements, are shown in Figure 5. The appropriate parameters used are summarized in Table 1. Note that the quartz dissolution rate is influenced by $\mathrm{pH}$ of the solution - but no change in $\mathrm{pH}$ results from the dissolution process. Although the dissolution rate will increase with an increase in $\mathrm{pH}$ (e.g., Dove and Elston, 1992), the measured condition of $\mathrm{pH} \sim 7$ is applied for both experiments. Also note that as the stress intensity factor is proportional to $\sqrt{r}$ (see Eq. (3)), the different values of " $r$ " ranging 1-5 $\mu \mathrm{m}$ are used for the predictions as a parametric study, resulting in no significant discrepancy which is predicted between these values. As is apparent in Figure 5, the predictions for the mechanisms of stress corrosion are in good agreement with the actual data while those assuming pressure solution significantly underestimate actual measurements, as documented in past studies (YAsuHara et al., 2004, 2006b). This mismatch implicates subcritical crack extension as the dominant mechanism contributing to compaction in early time and at lower temperatures.

For both Nova I and II, relations between fracture closure rates and stress intensity factors (when $r=1 \mu \mathrm{m}$ ) predicted under various temperature conditions, are depicted in Figure 6. Under isothermal conditions the relation is uniquely identified, and the closure 
(a) Novaculite I $\left(20 \& 80^{\circ} \mathrm{C}\right)$

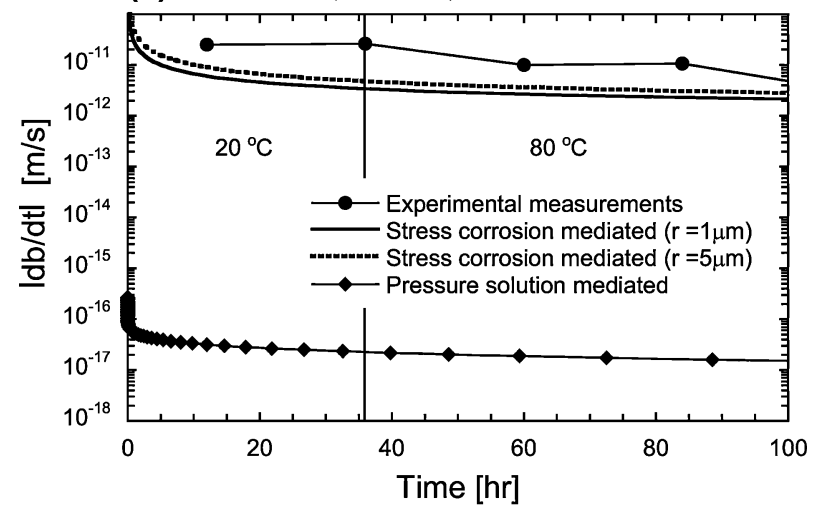

(b) Novaculite II $\left(20^{\circ} \mathrm{C}\right)$

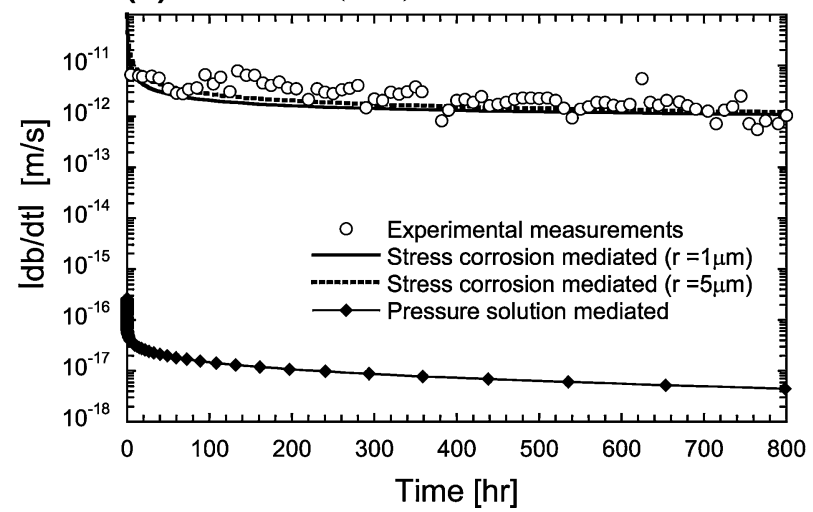

Figure 5

Comparisons of aperture closure rates between the experimental measurements and the predictions driven by stress corrosion and pressure solution; (a) Nova I (measurements after PolaK et al., 2003) and (b) Nova II (those after YASUHARA et al., 2006). As is apparent, the stress corrosion model adequately replicates the experiments, whereas the pressure solution results underestimate observed rates by about 5 orders of magnitude, indicating that the compaction of the fractures may be, at least in early and cool periods of the experiments, dominated by stress corrosion rather than pressure solution.

rates increase with an increase in temperature (see Eqs. (2) and (7)). In contrast, under isobaric conditions the relation between fracture aperture and stress intensity factor (Figure 7) is independent of applied temperature and instead is controlled by contact-area ratio, corresponding to stress intensity factor (see Eqs. (3)-(5)), as defined by Eq. (12). Apparent in experimental data (Widerhorn, 1978; Simmons and Freiman, 1980; Michalske, 1983), there exists a stress corrosion limit, $K_{0}$ (Figure 1), below which no subcritical crack growth (or fracturing) occurs. DunNING et al. (1993) explored this limit for quartz samples in the presence of water at ambient temperatures, and concluded that it is in the range $0.3-0.4 \mathrm{MPa} \mathrm{m}^{1 / 2}$. This is congruent with the analysis completed here, 


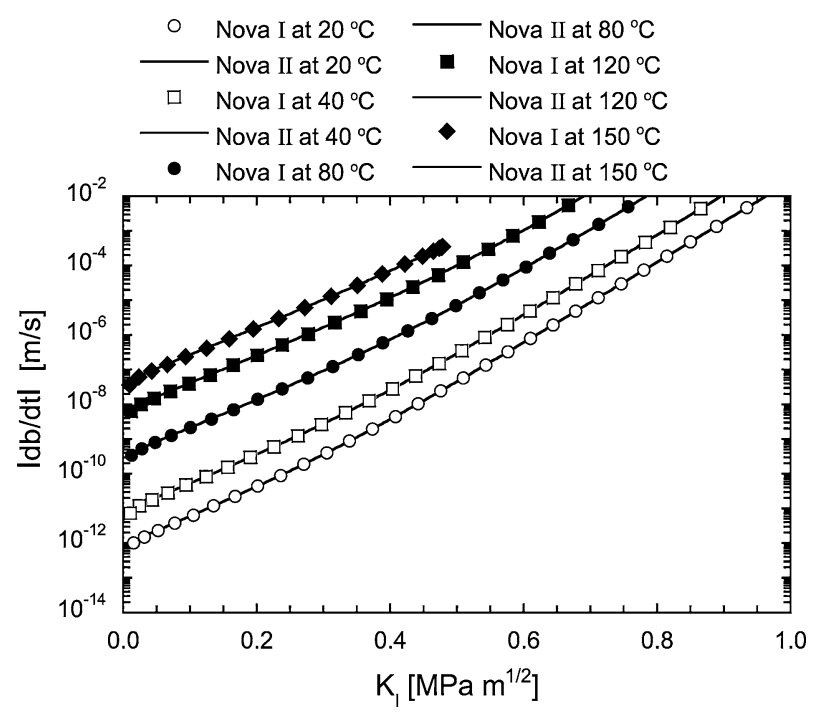

Figure 6

Relation between aperture closure rates and stress intensity factors. It is dependent only on temperatures applied, and not on stresses exerted, showing the equivalent trajectories between Nova I and Nova II at the same temperatures (see Eq. (1)).

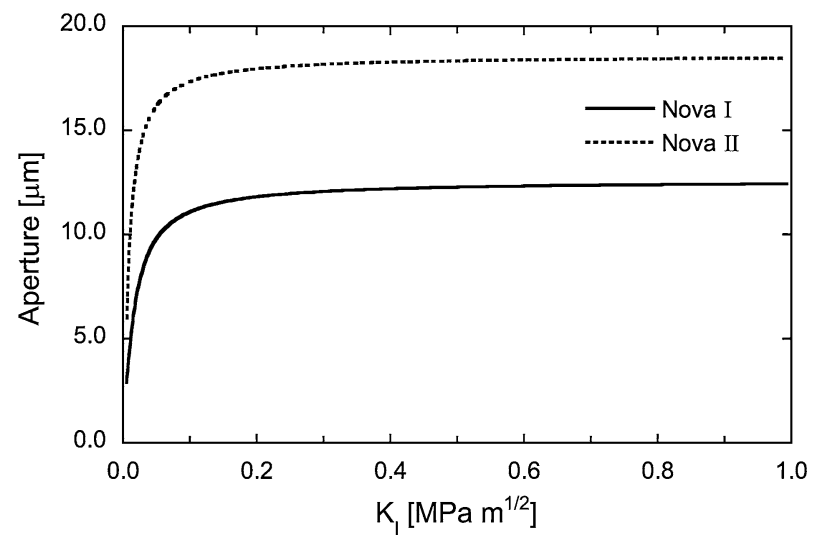

Figure 7

Relation between aperture and stress intensity factor. It is independent of applied temperatures, and uniquely identified by the relation between aperture and contact-area ratio (Eq. (10)).

with subcritical crack growth being a feasible mechanism at larger apertures, but potentially being replaced by other mechanisms at smaller aperture where the contact area grows. This is apparent in the calculations for this data set (Figure 7) where stress intensity factors are small $\left(K_{\mathrm{I}}<0.1 \mathrm{MPa} \mathrm{m}^{1 / 2}\right)$ where the aperture is also small. 


\section{Implications}

Under ambient stress (2.73 MPa for Nova I and $1.38 \mathrm{MPa}$ for Nova II) and temperature $\left(20^{\circ} \mathrm{C}\right)$ conditions apparent in the experiments, observed fracture closure rates closely match those predicted by subcritical crack growth (see Figure 5). These observed closure rates are much considerably than those predicted by pressure solution, where a consistent set of kinetic parameters are applied. The consistency of the predictions may be examined by changing the stress and temperature conditions, applied to the sample, and in examining the congruence between the observed changes and predictions, for each of the appropriate mechanisms.

Fracture closure rates moderated by both stress corrosion and by pressure solution are represented for a variety of stresses (or exerted effective stresses of 1,5, and $10 \mathrm{MPa}$ ) and temperatures $\left(20,50,100\right.$, and $\left.150^{\circ} \mathrm{C}\right)$, as illustrated in Figure 8. Both suites of predictions are completed using the same relation between fracture aperture and contactarea ratio (Eq. 12) measured for Nova II, and $r$ equal to $1 \mu \mathrm{m}$. As is apparent in Figure 8, at any selected condition of either stress or of temperature, the predicted closure rates for stress corrosion are greater than those predicted from pressure solution. Consequently, the time taken to reach the completion of closure (i.e., the arrest of fracture closure) is shorter for subcritical crack growth, than for pressure solution. The practical implication for this is that conditions of subcritical crack growth conclude within relatively short durations, and may be followed by extended periods of pressure solution which have a relatively smaller effect. Moreover, the progress of pressure solution is strongly influenced by temperature - predicted rates which span almost four orders of magnitudes at temperatures ranging from $20-150^{\circ} \mathrm{C}$. This contrasts with stress corrosion which is considerably less sensitive to applied temperatures. Interestingly, the evolution in overall fracture closure rates involving both stress corrosion and pressure solution approaches an asymptote as,

$$
\left|\frac{d b}{d t}\right|=\frac{C}{t^{n}},
$$

where $C$ and $n$ are constants that are dependent on applied stress and temperature. Figure 9 shows experimental results from the two experiments identifying the change in closure rate with test duration. The regression data fit experimental observations, enabling the constant, $C$, and the exponent, $n$, to be determined. The larger magnitude of the exponent, $n$, obtained for Nova I likely results from the larger effective stress applied, relative to that for Nova II. The greater the applied stress, the greater the resulting fracture closure rate, since stress concentration magnitudes will be correspondingly amplified, and the faster the closure rate will diminish, as fracture closure and growth in the contact area will ameliorate the local stress magnitudes.

This resulting relation is very simple, but appears to capture the gross aspects of the observed response. Once the evolution of aperture is predicted, the related, evolving permeability in fractures or faults may also be inferred. Therefore, it may be useful in 

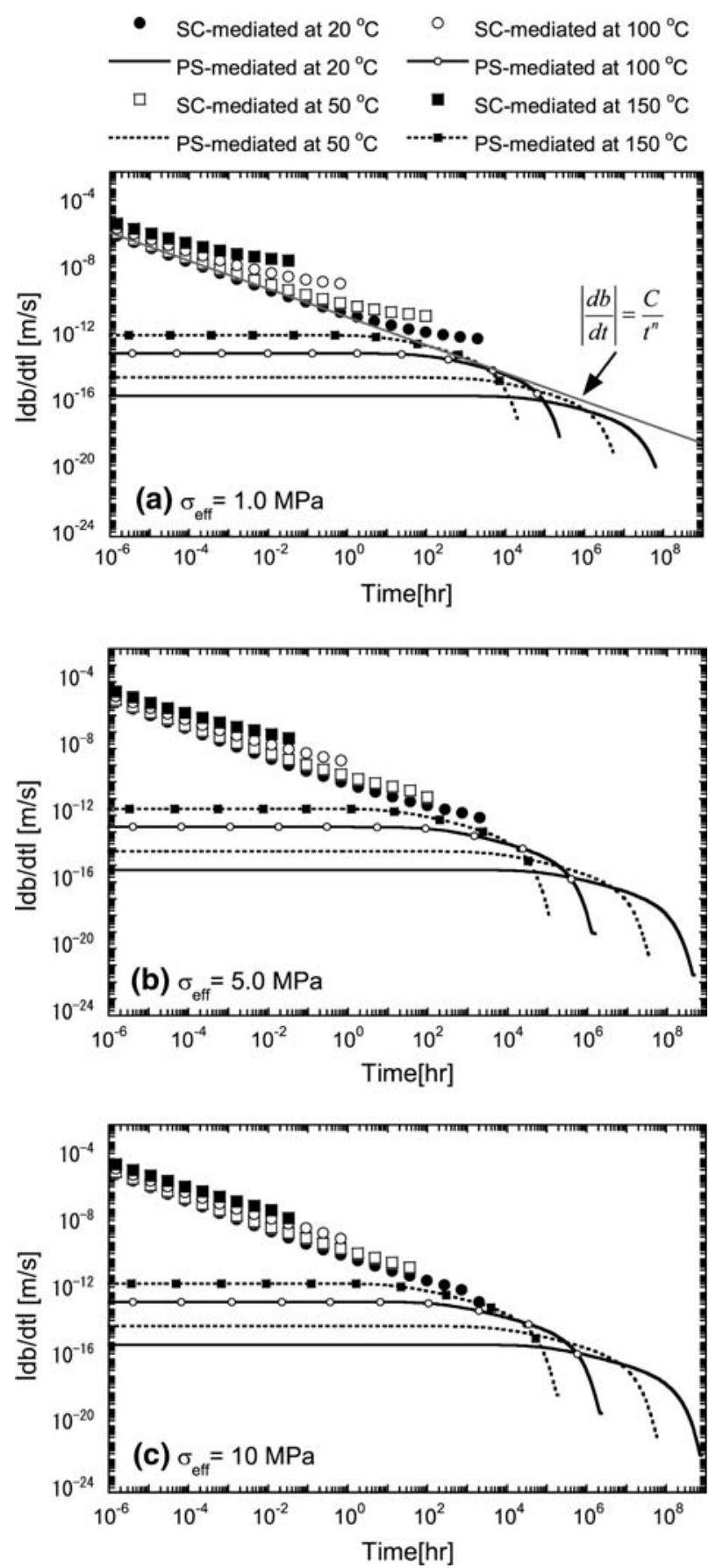


\section{Figure 8}

Time-dependent evolution of aperture closure rates moderated by stress corrosion and pressure solution, estimated under various temperatures $\left(20-150^{\circ} \mathrm{C}\right)$ and stress $(1-10 \mathrm{MPa})$ conditions. Closure rates mediated by stress corrosion are always greater than those by pressure solution. However, the effects of pressure solution may be exerted longer than the other. The convolved behavior (i.e., stress corrosion + pressure solution) may approach an asymptote depicted with a grey line in (a).

developing constitutive equations to represent the long-term evolution of fracture permeability, where chemical and mechanical effects have major impact, likely including the development and evolution of fault sealing during interseismic periods, of diagenetic compaction, of reservoir seals, and of flow paths. This work implicates that the rates and magnitude of fracture compaction (or related permeability) are relatively significant even under low or moderate pressure $(<10 \mathrm{MPa})$ and temperature $\left(<100^{\circ} \mathrm{C}\right)$ conditions, contrasting that these processes have been examined under higher pressure and temperature conditions in the literature.

\section{Conclusions}

This work examines the evolution in fracture aperture mediated by mechanically- and chemically-induced dissolution. Two straightforward conceptual models are developed to represent the effects of stress corrosion, and of pressure solution. Specifically, these models are applied to represent observed abrupt decreases in the fracture aperture during the early periods of experiments. These behaviors are well-replicated by supposed mechanisms of stress corrosion, which accommodates the initial rapid closure observed under low temperatures. Representing these early-term observations by pressure solution,

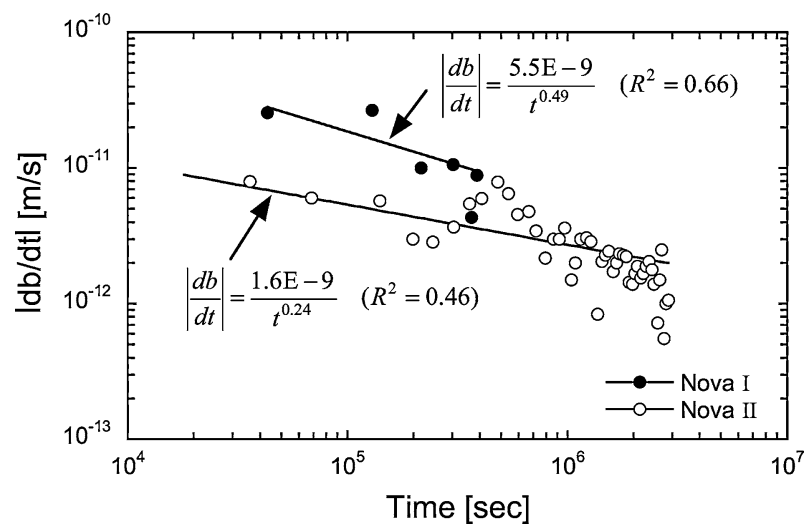

Figure 9

Regressed results using the simple relation of Eq. (15). The effective stress for Nova I is greater than that for Nova II, likely resulting in the larger number of $\mathrm{n}$. The simple relation may be applicable to describing evolution in the fracture aperture. 
using consistent kinetic parameters for quartz, significantly underestimates observed rates of closure, by several orders of magnitude. This implicates stress corrosion cracking as a feasible mechanism to explain these time-dependent observations, especially in the short-term and at low ambient temperatures, where pressure solution is anticipated to be rate-limited or inactive. However, microstructures have not been observed pre- and postexperiment in Nova I and II. These observations would be useful in discriminating between modes of deformation occasioned by pressure solution, and by subcritical crack growth. However, the mode of evolution, with subcritical crack growth occurring in the short time and at low temperatures, may be obliterated by the future operation of pressure solution, since all experiments were conducted at low temperature and then switched to higher temperature. Experiments conducted in reverse order, returning to low temperature, would be worthwhile to discriminate between mechanisms by attempting to observe the effects of subcritical crack growth, unmasked by overprinted effects of pressure solution.

An investigation of rates and magnitudes of aperture reduction, using models for stress corrosion and pressure solution highlights the differences in anticipated response. For a choice of consistent kinetic parameters, and for a given fracture topography, this illustrates that aperture closure rates are always greater for stress corrosion cracking, than for pressure solution. However, the dominance of stress corrosion over pressure solution may be transient and subsequent compaction by pressure solution may overtake it as the stress-corrosion-mediated compaction slows and ultimately ceases. These analyses, for either stress corrosion or for pressure solution, result in a straightforward rate law for compaction rate versus time. This simple phenomenological relation, whose parameters can be experimentally constrained, may be applied to estimate the long-term evolution of fracture compaction, and the corresponding evolution of transport properties.

\section{Acknowledgements}

This work has been supported by the Research Promotion Award of Ehime University and the Grant-in-aid for Young Scientists (B) (20760315), and by the US Department of Energy under grants DE-PS-36-04GO94001 and DE-AC02-05CH11231. This support is gratefully acknowledged. The comments of anonymous reviewers contributed significantly to the quality of the final manuscript. The conclusions reported here are those of the authors.

\section{REFERENCES}

Anderson, O. L. and Grew, P. C. (1977), Stress corrosion theory of crack propagation with applications to geophysics, Rev. Geophys. 15, 77-103. 
Atkinson, B. K. (1979), A fracture mechanics study of subcritical tensile cracking of quartz in wet environments, Pure and Appl. Phys. 117, 1011-1024.

Atkinson, B. K. and Meredith, P. G. (1981), Stress corrosion cracking of quartz: a note on the influence of chemical envinronment, Tectonophysics, 77, T1-T11.

AtKinson, B. K. (1984), Subcritical crack growth in geological materials, J. Geophys. Res. 89(B6), 4077-4114.

Atkinson, B. K., Fracture Mechanics of Rock, 534 pp., (Academic Press, London. 1987).

Charles, R. J. (1958), Static fatigue of glass, J. Appl. Phys. 29, 1549-1560.

Chester, J. S., Lenz, S. C., Chester, F. M., and Lang, R. A. (2004), Mechanisms of compaction of quartz sand at diagenetic conditions, Earth Planet. Sci. Lett. 220(3-4), 435-451.

Den BRoK, B., ZAhID, M., and PAsschier, C. (1998), Cataclastic solution creep of very soluble brittle salt as a rock analogue, Earth Planet. Sci. Lett. 163, 83-95.

DEWERs, T. and HAJASH, A. (1995), Rate laws for water-assisted compaction and stress-induced water-rock interaction in sandstones, J. Geophys. Res. 100, 13,093-13,112.

Dove, P. M. (1994), The dissolution kinetics of quartz in sodium chloride solutions at $25^{\circ}$ to $300^{\circ} \mathrm{C}$, Am. J. Sci., 294, 665-712.

Dove, P. M. (1995), Geochemical controls on the kinetics of quartz fracture at subcritical tensile stresses, J. Geophys. Res. 100(B11), 22,349-22,359.

Dove, P. M. and CRerar, D. A. (1990), Kinetic of quartz dissolution in electrolyte solutions using a hydrothermal mixed flow reactor. Geochim. Cosmochim. Acta 54, 955-969.

Dove, P. M. and Elston, S. F. (1992), Dissolution kinetics of quartz in sodium chloride solutions: Analysis of existing data and a rate model for $25^{\circ} \mathrm{C}$, Geochim. Cosmochim. Acta 56, 4147-4156.

Dunning., J., McDonald, S. K., Douglas, B. J., and Dintaman, C. (1993), Measurement of the stress corrosion limit, $K_{0}$, in quartz and Na-lime glass, Int. J. Rock Mech. Min. Sci. Geomech. Abstr. 30(7), 687-690.

Elias, B. P. and Hajash, A. (1992), Changes in quartz solubility and porosity due to effective stress: An experimental investigation of pressure solution, Geology, 20, 451-454.

Evans, A. G. (1972), A method for evaluating the time-dependent failure characteristics of brittle materials and its application to polycrystalline alumina, J. Mater. Sci. 7, 1137-1146.

FENG, X:-T., CHEN, S., and LI, S. (2001), Effects of water chemistry on microcracking and compressive strength of granite, Int. J. Rock Mech. Min. Sci. Geomech. Abstr. 38(4), 557-568.

Freiman, S. (1984), Effects of chemical environments on slow crack growth in glasses and ceramics, J. Geophys. 89, 4072-4077.

Hutchings, I. M. Tribology: Friction and Wear of Engineering Materials, 273 pp. (Edward Arnold Publishers, London, 1992).

Johnson, K. L. Contact Mechanics, 452 pp. (Cambridge Univ. Press, New York, 1985).

Karner, S. L., Chester, F. M., Kronenberg, A. K., and Chester, J. S. (2003), Subcritical compaction and yielding of granular quartz sand, Tectonophysics 377, 357-381.

Lawn, B. R. and Wilshaw, T. R. Fracture of Brittle Solids, 204 pp. (Cambridge Univ. Press, New York, 1975).

Lawn, B. R. (1998), Indentation of ceramics with spheres: A century after Hertz, J. Am. Ceram. Soc., 81, 19771994.

Lee, V. W., Mackwell, S. J., and Brantley, S. L. (1991), The effect of fluid chemistry on wetting textures in novaculite, J. Geophys. Res. 96(B6), 10,023-10,037.

LEHNER, F.K. (1995), A model for intergranular pressure solution in open systems, Tectonophysics, 245, 153170.

LemeE, C. and GuÉGuen, Y. (1996), Modelling of porosity loss during compaction and cementation of sandstones, Geology 24, 875-878.

Michalske, T. A. The stress corrosion limit: Its measurement and implications, Frac. Mech. of Ceramics, 5 , pp. 277-289 (Plenum Press, New York 1983).

Nara, Y. and Kaneko, K. (2005), Study of subcritical crack growth in andesite using the Double Torsion test, Int. J. Rock Mech. Min. Sci. 42(4), 521-530.

Polak, A., Elsworth, D., Yasuhara, H., Grader, A., and Halleck, P. (2003), Permeability reduction of a natural fracture under net dissolution by hydrothermal fluids. Geophys. Res. Lett. 30(20):2020, doi:10.1029/ 2003GL017575.

RAJ, R. (1982), Creep in polycrystalline aggregates by matter transport though a liquid phase, J. Geophys. Res. 87, 4731-4739. 
Renard, F., Ortoleva, P., and Gratier, J. P. (1997), Pressure solution in sandstones: Influence of clays and dependence on temperature and stress, Tectonophysics, 280, 257-266.

Revil, A. (1999), Pervasive pressure-solution transfer: A poro-visco-plastic model, Geophys. Res. Let. 26, 255 258.

RoBIN, P.-Y. F. (1978), Pressure solution at grain to grain contacts, Geochim. Cosmochim. Acta 42, 13831389.

RutTer, E.H. (1976), The kinetics of rock deformation by pressure solution, Philos. Trans., R. Soc. London, A 283, 203-219.

Segall, P. (1984), Rate-dependent extensional deformation resulting from crack growth in rock, J. Geophys. Res. 89, 4185-4195.

Scholz, C. H. The Mechanics of Earthquakes and Faulting, 439 pp. (Cambridge Univ. Press, New York, 1990).

ShutJEns, P. M. T. M. (1991), Experimental compaction of quartz sand at low effective stress and temperature conditions, J. Geol. Soc. Lond. 148, 527-539.

Simmons, C. J. and Freiman, S. W. (1980), Effects of phase separation on crack growth in borosilicate glass, J. Non Cryst. Solids 38-39, 503-508.

Stephenson, L. P., Plumley, W. J., and Palciauskas, V. V. (1992), A model for sandstone compaction by grain interpenetration, J. Sediment. Petrol. 62, 11-22.

WeYL, P. K. (1959), Pressure solution and force of crystallization-A phenomenological theory, J. Geophys. Res. 64, 2001-2025

Wiederhorn, S. M. and Bolz, L. H. (1970), Stress corrosion and static fatigue of glass, J. Am. Ceram. Soc. 53, 543-548.

WIEDERHorn, S. M. Mechanism of subcritical crack growth in glass, Fract. Mech. Ceram. 4, pp. 549-580 (Plenum Press, New York. 1978).

Yasuhara, H., Elsworth, D. and Polak, A. (2003), A mechanistic model for compaction of granular aggregates moderated by pressure solution, J. Geophys. Res. 108(B11), 2530, doi:10.1029/2003JB002536.

Yasuahra, H., Elsworth, D., and Polak, A. (2004), Evolution of permeability in a natural fracture: Significant role of pressure solution, J. Geophys. Res. 109(B3), B03204, doi:10.1029/2003JB002663.

Yasuhara, H., Polak, A., Mitani, Y., Grader, A., Halleck, P., and Elsworth, D. (2006), Evolution of fracture permeability through fluid-rock reaction under hydrothermal conditions, Earth Planet. Sci. Lett. 244, 186200.

Yasuhara, H. and Elsworth, D. (2006), A numerical model simulating reactive transport and evolution of fracture permeability, Int. J. Numer. Anal. Meth. Geomech. 30, 1039-1062.

(Received October 29, 2007, accepted April 1, 2008)

Published Online First: July 31, 2008

To access this journal online:

www.birkhauser.ch/pageoph 